\section{Explorando el negacionismo del VIH/SIDA en idioma español, en internet}

\section{Exploring HIV denial in Spanish, in the internet}

\section{Sr. Editor:}

El virus de inmunodeficiencia humana (VIH) es un retrovirus que ataca al sistema inmune, predisponiendo al desarrollo del síndrome de inmunodeficiencia adquirida (SIDA) ${ }^{1}$. En el año 2013, según reportes de la Organización Mundial de la Salud, más de 35 millones de personas estaban infectadas por VIH, pero sólo 12,9 millones recibían tratamiento con antirretrovirales.

Los primeros casos de SIDA se reportaron alrededor del año $1981^{1,2}$, y en1983 se estableció la relación del VIH con el SIDA. Sin embargo, no mucho después algunas personas empezaron a negar la existencia del VIH y del SIDA ${ }^{1}$. Estas personas formaron diversos grupos que persisten en la actualidad, y son conocidos bajo el término de "Negacionistas del VIH/SIDA" (NVS)

Estos grupos han causado un gran daño a la lucha contra el VIH/SIDA. Talvez el ejemplo más representativo se haya presentado en 1999 cuando el presidente de Sudáfrica prohibió la entrada de antirretrovirales a este país, convencido de que no existía relación entre el VIH y el SIDA y que los antirretrovirales iban a causar más daño que la enfermedad, causando un estimado de 330.000 muertes ${ }^{4}$.

Asimismo, cada año miles de pacientes con VIH abandonan su tratamiento al ser convencidos por argumentos NVS 5 .

Uno de los medios de comunicación que usan los NVS es la internet, donde pueden divulgar sus argumentos a millones de personas, incluyendo pacientes que están buscando información sobre esta enfermedad. Sin embargo, poco se ha estudiado sobre la actividad de los NVS en internet ${ }^{5}$.

Con el objetivo de describir el contenido web en español que exhiba argumentos NVS, se realizó una búsqueda en Facebook y en Google durante mayo de 2015 utilizando los términos: (Negacionismo del VIH/SIDA), (VIH no causa SIDA), (Antirretrovirales son veneno), (farsa/mentira del VIH/SIDA), (Engaño del VIH/SIDA) (cura del
VIH/SIDA), (VIH/SIDA no existe), y (Conspiración del VIH/SIDA). Estos términos fueron seleccionados por ser los más utilizados en las páginas web en español dedicadas a dicho tema. Se revisaron los primeros 30 resultados para cada término, y se tabularon las características de aquellos que tuvieron entre sus temas principales el NVS y que hayan sido actualizadas alguna vez en el período 2008-2015 (Tabla 1).

Se obtuvo 14 resultados que cumplieron los criterios de inclusión: 2 páginas de Facebook, 1 blog, 3 foros, 4 páginas web, y 4 videos. Sólo 2 resultados tuvieron alguna actualización referente al tema durante el 2015, lo cual significa que algunos grupos NVS de habla hispana siguen activos en internet.

En 12 resultados la profesión de los autores no fue especificada. En un resultado, el autor, autoidentificado como médico, ofrecía brindar consultas a pacientes con VIH, evidenciando la actividad de personas que desinforman a la población con intereses económicos. Esto representa un riesgo para la salud de los pacientes que no estén adecuadamente informados sobre su condición ${ }^{5}$.

No todas las páginas analizadas presentaron los mismos argumentos NVS. Sin embargo, los pacientes pueden hacer caso omiso a esta falta de concordancia, y creer en las promesas de una cura rápida y milagrosa para su condición, abandonando el tratamiento médico, acelerando las complicaciones de su enfermedad e inclusive su muerte. Por ello, resaltamos la importancia de que el personal de salud gane la confianza de sus pacientes e invierta tiempo en advertirles sobre los argumentos NVS y sus consecuencias ${ }^{5}$. Asimismo, resulta necesaria la creación de un contenido web que se enfoque en desmentir los argumentos NVS.

\section{Alejandro Zevallos ${ }^{1, a}$ Álvaro Taype-Rondán ${ }^{2, b}$}

${ }^{1}$ Sociedad Científica de Estudiantes de Medicina de la Universidad de San Martín de Porres, Facultad de Medicina Humana, Universidad de San Martín de Porres, Lima, Perú.

${ }^{2}$ CRÓNICAS Centro de Excelencia en Enfermedades Crónicas, Universidad Peruana Cayetano Heredia, Lima, Perú.

${ }^{a}$ Estudiante de Medicina Humana. ${ }^{b}$ Médico-Cirujano. 


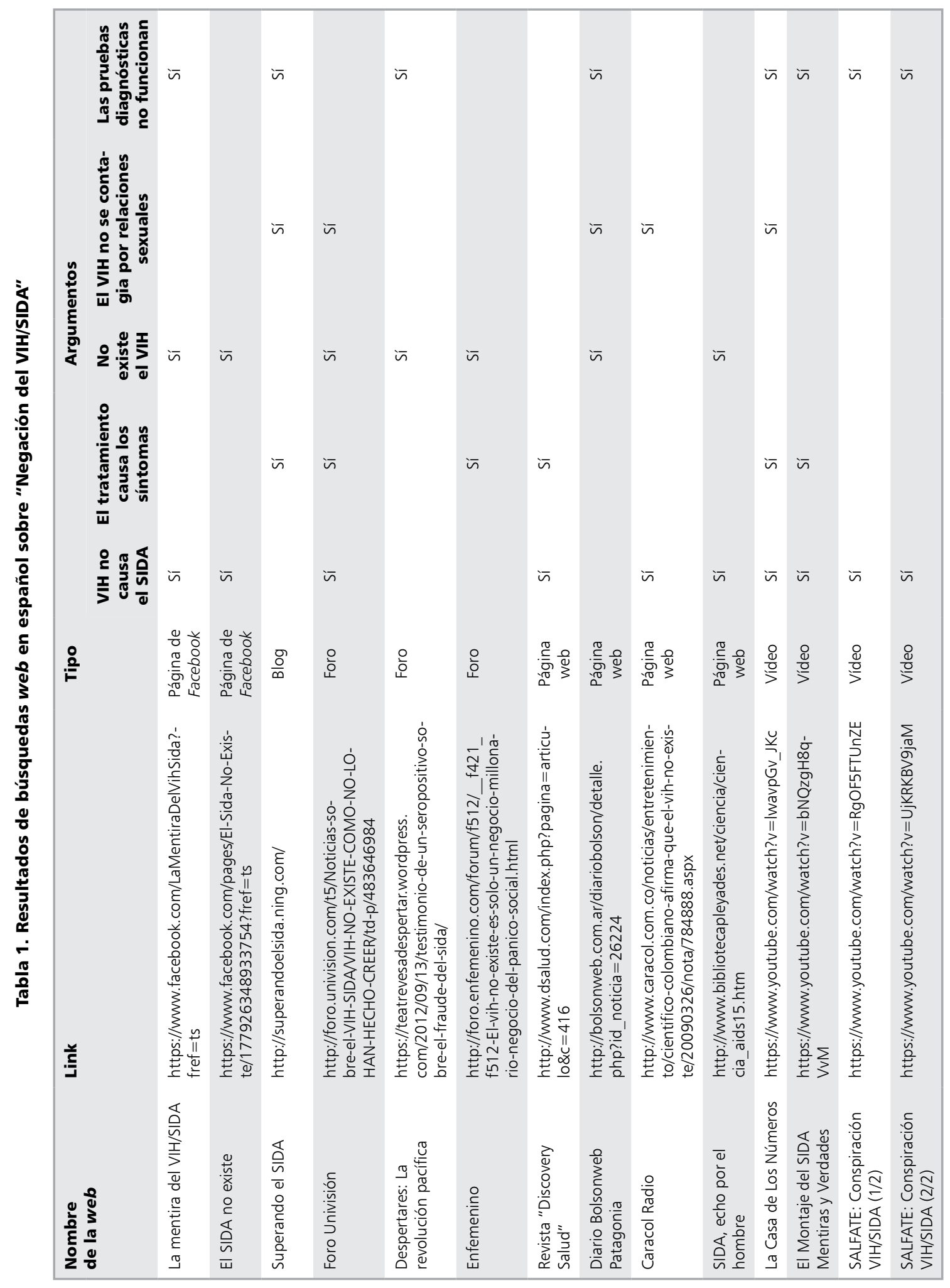




\section{Referencias}

1. O’Brien SJ, Goedert JJ. HIV causes AIDS: Koch's postulates fulfilled. Curr Opin Immunol 1996; 8 (5): 613-8.

2. Gallo RC, Sarin PS, Gelmann EP, Robert-Guroff M, Richardson E, Kalyanaraman VS, et al. Isolation of human T-cell leukemia virus in acquired immune deficiency syndrome (AIDS). Science 1983; 220 (4599): 865-7.

3. Duesberg PH. Human immunodeficiency virus and acquired immunodeficiency syndrome: correlation but not causation. Proc Natl Acad Sci USA 1989; 86 (3): 755-64.
4. Chigwedere P, Seage GR, 3rd, Gruskin S, Lee TH, Essex M. Estimating the lost benefits of antiretroviral drug use in South Africa. J Acquir Immune Defic Syndr 2008; 49 (4): 410-5.

5. Smith TC, Novella SP. HIV denial in the Internet era. PLoS Med 2007; 4 (8): e256.

Correspondencia a:

Alejandro Francisco Zevallos Morales

Santa Teresita 380 San Isidro. Lima, Perú.

alejandro.zevallos@hotmail.com 